\title{
Henri Pirenne - Considerações sobre sua obra historiográfica
}

\author{
Henri Pirenne - Considerations about his historical work
}

\author{
José D’Assunção Barros ${ }^{1}$
}

\section{RESUMO}

Este artigo analisa e discorre sobre as principais contribuições do historiador belga Henry Pirenne tanto para historiografia no sentido mais restrito - aqui considerado o campo mais amplo da Teoria e Metodologia da História - como para a historiografia medievalista de sua época, considerando que esta temporalidade foi o principal campo de estudos percorrido pelo interesse de Pirenne. Ao lado das teses originais de Pirenne sobre a formação e declínio da Idade Média, o desenvolvimento das cidades neste período e a reintensificação do comércio de longa distância, examina-se o debate que se estabeleceu nas décadas seguintes em contraposição a algumas das propostas pirennianas para a compreensão do período medieval.

Palavras-chave: Pirenne. Historiografia. Debates medievalistas.

\section{ABSTRACT}

This article analyze and discuss the main contributions of the belgian historian Henry Pirenne for both Historiography - here considered the broader field of Theory and Methodology of History - as to the medievalist historiography of his time, considering that this temporality was the main field of studies covered by the interest of Pirenne. Besides the original Pirenne'a thesis on the formation and decline of the Middle Ages, the development of cities in this period and intensification of long-distance trade, it is examined the great debate that was established in the following decades about some of the proposals of Pirenne to understand the medieval period.

Keyword: Pirenne. Historiography. Medievalists debates.

1 Professor-Adjunto nos cursos de graduação e pós-graduação em História da Universidade Federal Rural do Rio de Janeiro. Professor Colaborador do Programa de Pós-Graduação em História Comparada da Universidade Federal do Rio de Janeiro. Doutor em História pela Universidade Federal Fluminense. Autor de livros na área de Teoria da História e Historiografia, entre os quais a série Teoria da História, publicada pela Editora Vozes. 


\section{Introdução: Um historiador belga}

Henri Pirenne, nascido em Versviers (Bélgica) em 1862, foi seguramente um dos mais importantes historiadores europeus das últimas décadas do século XIX e primeiras décadas do século XX. A importância de sua obra se desdobra em três aspectos: a contribuição para uma nova História da Bélgica, em sua própria época; a contribuição para o desenvolvimento da historiografia em geral nas gerações seguintes; e a contribuição específica como medievalista, fundamental, embora algumas de suas teses tenham sido posteriormente criticadas em alguns aspectos essenciais. Os dois últimos aspectos interessam mais a este artigo, no qual procuraremos examinar tanto as contribuições de Pirenne para uma nova historiografia que logo teria à sua testa historiadores como Lucien Febvre e Marc Bloch, como também as impactantes contribuições do historiador belga para a historiografia medieval.

Algumas palavras, porém, podem ser ditas sobre a importância de Pirenne para o desenvolvimento de uma historiografia específica sobre a Bélgica. Esta parte de sua obra, a menos conhecida fora de seu próprio país, de fato ocupou trinta e sete anos da atividade historiográfica de Pirenne, ao mesmo tempo em que ele desenvolvia outros estudos de alcance mais amplo e importância mais geral para a historiografia européia. Os sete tomos da História da Bélgica (1900-1931), de Pirenne, tiveram uma importância extraordinária para a historiografia belga não apenas pelo rigor documental e pela análise historiográfica voltada para todas as instâncias da sociedade (política, econômica, cultural), mas particularmente por ter demonstrado que a Bélgica não era uma criação artificial e circunstancial, e sim um país cuja identidade vinha se afirmando desde o período medieval. Esse aspecto foi fundamental para a história de seu país, que finalmente encontrava o seu grande historiador nacional, ao mesmo tempo em que ia ao encontro de uma identidade viva e específica que havia sido negligenciada pela historiografia anterior. Sobretudo, e este é um aspecto que já alçaria Pirenne na direção de uma contribuição historiográfica mais ampla, vemos emergir nesta grande História da Bélgica (1900-1931) a função das cidades um dos principais temas ao qual se dedicou Pirenne em toda a sua vida historiográfica.

\section{As influências recebidas por Pirenne}

Antes de discorreremos sobre a contribuição mais consistente de Pirenne para a historiografia ocidental como um todo - ou seja, sua influência sobre uma nova historiografia que já seria tipicamente contemporânea, e sua contribuição mais específica 
como historiador medievalista - será oportuno ressaltar as influências que recebeu de outros historiadores, e as influências que ele mesmo exerceria sobre outros. Sobre o primeiro item, podemos ressaltar alguns autores que fazem parte da rede interautoral que fornece a Pirenne um ambiente teórico e historiográfico importante. Como Pirenne formouse e completou a sua formação entre três países - primeiro a Bélgica, depois a França, e finalmente a Alemanha - teremos no seu acorde historiográfico desde a presença de notas de influência mais locais, como a do medievalista belga Godefroid Kurth (1847-1916), como a de notas de maior penetração na historiografia européia: Arndt, Bresslau, Lamprecht e Schmoller.

Godefroid Kurth, medievalista belga hoje pouco conhecido, representou o contato e impulso inicial de Pirenne para o estudo da História, contrariando os planos familiares que lhe indicavam uma carreira no Direito. Kurth certamente contribuiu não apenas para direcionar Pirenne para o estudo da Idade Média, como também para a sua abertura temática². Além disto, Kurth era já um historiador problematizador, e fazia, no título de um de seus livros, uma pergunta que mais tarde seria central na obra de Pirenne: O que é a Idade Média? (1897). Esse empenho em repensar de uma nova maneira as fronteiras historiográficas entre as grandes eras, que veremos tão claramente em Pirenne, foi uma primeira influência recolhida de Godefroid Kurth, que também estenderia para Pirenne a sua preocupação com A Nacionalidade Belga (1913).

De Gustav von Schmoller (1838-1917) - professor de Economia Política nas universidades de Halle (1864-1872), Estrasburgo (1872-1882) e Berlim (1882-1913) - Pirenne herdaria a preocupação central com a dimensão econômica para a análise histórica. Pode-se dizer que o economista-historiador Schmoller estendeu uma ressonância fundamental sobre o historiador-economicista Henri Pirenne, que soube desenvolver à sua maneira este encontro fundamental entre economia e história. Schmoller foi um dos impulsionadores da escola alemã da Economia Histórica, e era um intelectual atento não apenas à Economia e à História, como também ao Direito - três aspectos que também veremos ocupar uma posição central em Pirenne. Sua abordagem da economia através da história também pressupunha uma análise comparativa no tempo e no espaço, uma instância adicional que também veremos em Pirenne, um dos primeiros a propor uma abordagem especificamente comparada da História, conforme veremos mais adiante. A teoria das etapas da evolução econômica - configurando as economias aldeãs, citadina, territorial, nacional e mundial também pode ser atribuída a Schmoller, e logo veremos as ressonâncias da mesma no acorde historiográfico de Pirenne, que dedicou especial atenção a analisar a passagem de aldeias medievais à dimensão da cidade, a inserção das cidades medievais em um território

2 Depois de uma tese sobre Catão, o antigo (1872), Kurth se direciona progressivamente para o estudo da Idade Média, a princípio com um ensaio sobre Gregório de Tours e os estudos clássicos no século VI(1878), e depois se aventurando por temas diversos como a Lepra no Ocidente das Cruzadas (1891, a História Poética dos Merovíngios (1893), e uma História medieval da Cidade de Liège (1909-1910), obras às quais se podem acrescentar biografias como as de Clóvis (1896) e São Bonifácio (1902). 
mais vasto, e, finalmente, a integração destas a uma rede mais ampla a partir do comércio de longa distância.

Também podemos entrever nesta rede inter-autoral a importância de Karl Gotthard Lamprecht (1856-1915), um historiador igualmente preocupado com a importância da instância econômica para a história ${ }^{3}$, e que se notabilizaria particularmente por sua ultrapassagem dos estreitos limites da historiografia política tradicional e por sua atenção mais específica aos aspectos culturais, a tal ponto que, por sua singular atenção tanto à economia, à cultura, e mesmo a aspectos psicológicos, chegou a atrair contra si hostilidades dos historiadores estritamente políticos das universidades alemãs ${ }^{4}$. É interessante, aliás, visualizar esta rede interautoral que liga Lamprecht aos próprios jovens historiadores dos Annales, um pouco diretamente, e um pouco através do próprio Henri Pirenne. Em 1900, Lamprecht publicaria uma obra intitulada A Abordagem Histórico-Cultural (1900), e suas inquietações sobre o que deveria ser a História também estão expressas em sua obra $O$ que é a História? (LAMPRECHT, 1905). Lamprecht, aliás, um historiador que já pensa a História de maneira interdisciplinar em sua própria época, também criará em Leipzig um Instituto de História Comparada. Entre outros itens remarcáveis, antecipa a reflexão sobre "mentalidades" de Lucien Febvre, embora direcionadas para a tentativa de identificar uma psicologia típica de cada nação, e não são de se estranhar as hostilidades sofridas por Lamprecht em função de sua abertura interdisciplinar e multi-temática, no seio de uma instituição alemã ainda francamente dominada pela história política tradicional. Para o caso de Pirenne, historiador dez anos mais novo, vemos que o mundo historiográfico já começava cada vez mais a se abrir a novas possibilidades. De fato, foi à geração historiográfica de Pirenne, imediatamente anterior à de Febvre (1878-1956) e Marc Bloch (1886-1944), que coube preparar esta abertura contra uma historiografia predominantemente política que ainda grassava na Alemanha e na França.

A influência de Harry Bresslau (1848-1926) - historiador alemão que foi cofundador dos Monumenta Germanica - apresenta-se na preocupação fundamental do primeiro Pirenne em editar documentos. A primeira cadeira universitária de Pirenne, em Liège, foi um curso sobre Diplomacia e Paleografia (1895), e sua preocupação com os problemas da crítica documental era nítida nestes primeiros tempos. A essa altura, Pirenne já fora convidado para escrever uma História da Bélgica, e começara por atualizar um estudo anterior de modo a constituir consistente Bibliografia da História da Bélgica que expunha cuidadosamente tanto as fontes disponíveis para o estudo da história do país, como o estado da historiografia

3 Uma das primeiras obras de Lamprecht é constituída por três volumes sobre $A$ Vida Econômica da Alemanha na Idade Média (1885-1886). Também Pirenne publicaria a sua História Econômica e Social da Idade Média (1933), originalmente apresentada como uma contribuição à História Geral de Gustav Glotz, e desde então republicada diversas vezes em separado. Com relação às interações entre Pirenne e Lamprecht, ver Lyon (1974, p. 128). Um estudo sobre a correspondência entre Lamprecht e Pirenne pode ser encontrado em Lyon (1966, p. 161-231).

4 Para um estudo sobre esta polêmica, ver Iggers (1988, p. 197-200). 
já realizada ${ }^{5}$. Estas primeiras realizações, deste modo, inserem Henri Pirenne em um diálogo com os historiadores que, nos diversos países, ocupavam-se com a sistematização documental e historiográfica. Para este aspecto, Harry Bresslau foi o seu grande modelo.

Considerando que uma rede inter-autoral faz-se também através da ligação de autores que não conviveram diretamente, mas que ressoam uns sobre os outros através das pontes bibliográficas e da própria retransmissão através de uma cadeia de autores, podemos citar ainda a influência de E. Moritz Arndt (1769-1860), alemão nacionalista atuante nas seis primeiras décadas do século XIX. A tônica do nacionalismo foi uma importante influência inicial sobre o Pirenne elaborador de uma História da Bélgica preocupada em restabelecer a identidade histórica de seu país. Em Espírito do Tempo (1806) - no contexto de oposição à expansão napoleônica - Arndt já havia enfatizado a necessidade de respeito pelas particularidades nacionais em contraposição ao peso dado às abstrações universalistas, erigindo-se em defensor do direito dos povos e das nações com base na sua história, uma questão cara ao Henri Pirenne que, nos primeiros volumes de História da Bélgica, buscava a identidade belga nos primórdios medievais.

Esta nota de ênfase nacionalista, todavia, parece inverter sua ressonância no Pirenne de depois da Primeira Grande Guerra - agora um historiador decepcionado com os rumos impressos pelo padrão nacionalista que havia ajudado a deflagrar o primeiro conflito de proporções macro-europeias e que, desde então, motivava o historiador belga a pensar nas possibilidades de uma história comparada da Europa, projeto que logo seria retomado por Marc Bloch 6 . É interessante observar, aliás, o gradual deslocamento de um primeiro Pirenne, particularmente preocupado em seguir os conselhos de Arndt na busca por homens concretos que devem ser contrapostos às abstrações, para a tendência do último Pirenne a minimizar essa vida individual diante das grandes forças econômicas que a limitam. Da habilidade pirenniana de seguir atentamente a trajetória de indivíduos que possam iluminar uma questão histórica específica, presta-nos um bom testemunho a passagem de Cidades na Idade Média (1980, p.92-94), na qual o historiador belga segue a trajetória de São Godric de Finchale (1065-1170), o camponês que vira mercador e depois santo, e que, ao ter sua vida descrita em detalhes por uma hagiografia, permite-lhe aventar hipóteses sobre todo um padrão de surgimento de novos mercadores a partir de fins do século XI. Mais adiante abordaremos as críticas às generalizações de Pirenne para o caso medieval. De todo modo, sobre o deslocamento de Pirenne para uma historiografia de grandes e brilhantes pinceladas que se arrisca a grandes generalizações, podemos evocar o depoimento de Leopold Genicot (1914-1995), historiador belga que escreveu o verbete sobre Pirenne para a

5 Referimo-nos à Organização dos estudos de história provincial e local da Bélica (PIRENNE, 1885, p. 113-138). Para uma recepção de época da História da Bélgica de Pirenne, ver Kurth (1899, p. 21-25);

6 Ernst Moritz Arndt (1769-1860) - ensaísta, poeta e ativista político envolvido na campanha pela abolição da servidão e nas primeiras lutas pela unificação alemã - escreveu, aliás, um ensaio sobre a Holanda: The Netherlands question (1831). Entre 1802 e 1804, Arndt empreendeu também uma viagem de estudos que cobriu a Alemanha, Hungria, Áustria, Itália, França, e, por fim, a própria Bélgica. 
Enciclopédia de Ciências Históricas (GENICOT, 1993, p. 597-599), e que com ele conviveu quando aluno:

Ele chegou, na verdade, em seus últimos anos, a medir menos a parte dos indivíduos, a do acaso, e a dos outros fatores da civilização; ele disse-me, em 1933, que 'a torneira da economia deixa cair água demais', O gosto pela síntese, os vastos panoramas, as explicações universais, o que o levou a generalizações apressadas e frágeis, que não repousavam em despojamentos exaustivos e ainda menos em enumerações e contagens. Um ensino repleto de calor e de força e obras servidas por uma língua clara, alerta, até mesmo colorida difundiram e impuseram suas opiniões (GENICOT, 1993, p. 598)7.

\section{A influência de Pirenne sobre as demais gerações de historiadores}

Se há uma rede inter-autoral que ressoa em Pirenne, este, por outro lado, seria uma nota de influência importante para os acordes historiográficos de um grande número de historiadores das gerações seguintes. A herança pirenniana mais célebre é aquela que é reivindicada pelos historiadores dos Annales, a começar por Lucien Febvre e Marc Bloch. Em um primeiro momento, aliás, os fundadores dos Annales chegaram a propor a Pirenne que este fosse o líder da nova Revista dos Annales. Marc Bloch cita Pirenne diversas vezes em sua Apologia da História (2001, p. 65). Além da óbvia atenção ao Econômico como uma instância central para a compreensão histórica, Bloch elogia a sua erudição, a amplitude do seu olhar, e, sobretudo, a sua integração ao Presente e à própria vida:

Eu estava acompanhando, em Estocolmo, Henri Pirenne. Mal chegamos, ele me diz: ' $\mathrm{O}$ que vamos ver primeiro? Parece que há uma prefeitura nova em folha. Comecemos por ela'. Depois, como se quisesse prevenir um espanto, acrescentou: 'Se eu fosse antiquário, só teria olhos para as coisas velhas. Mas sou um historiador. É por isso que amo a vida (BLOCH, 2001, p. 65).

A menção a Pirenne nas sucessivas gerações de historiadores dos Annales pode ser compreendida quando lembramos que o historiador belga ofereceu ao mundo historiográfico de sua época uma contribuição particularmente audaciosa. Esteve sempre propondo novos problemas e hipóteses, mesmo que algumas de suas teses tenham sido 
posteriormente criticadas. Ao pensar a historiografia nos termos de uma história-problema - mesmo sem utilizar esta expressão, que seria de Febvre - Pirenne antecipou de certo modo o "espírito dos Annales". Outro ponto de contato com este movimento em formação foi a consciência das temporalidades como alteridades a serem compreendidas. Henri Pirenne sempre se preocupou particularmente em redefinir as fases históricas que já iam se estagnando em tábuas de leituras que ameaçavam se tornar consensuais, como se a Antiguidade, a Idade Média e a Modernidade fossem grandes eras já dadas, e que não precisavam ser problematizadas. Era comum, à sua época, confiar exclusivamente no desaparecimento político do Império Romano do Ocidente após o impacto das invasões germânicas e extra-européias para estabelecer uma fronteira rigorosa entre Anriguidade e Medievalidade. Mas Pirenne ousou perguntar: "o que é a Idade Média". Hoje, a percepção de uma fronteira móvel entre estes dois períodos, conforme o problema que centralize a análise historiográfica, já não é novidade, e historiadores diversos lidam com conceitos problematizadores como o de "antiguidade tardia" e com oscilações diversas relacionadas ao trânsito do mundo romano para o ocidente medieval. Mas era de fato um problema novo, ou um novo olhar historiográfico, o que foi apresentado quando Pirenne propôs considerar o surgimento do fenômeno islâmico, e sua contrapartida - a consolidação do mundo carolíngio em uma Europa que se interiorizava - como instauradores de um novo período. Essa capacidade de ver as coisas de uma nova maneira - mais do que as respostas específicas que deu aos problemas por ele mesmo levantados - foi a contribuição maior que aproximou Pirenne e os novos historiadores dos Annales.

Havia ainda a questão da História Econômica. A Economia já havia oferecido escolas de economia histórica, e já surgiam no horizonte as primeiras experiências com a quantificação histórica. Marx e Engels já haviam fixado as bases fundamentais de um novo paradigma historiográfico que trazia a Economia para o primeiro plano de análise; contudo, à época de Pirenne, ainda não haviam despontado as primeiras análises historiográficas, elaboradas por historiadores profissionais de formação, empreendidas sob esta nova perspectiva. $\mathrm{O}$ olhar historiográfico trazido por Pirenne na segunda e terceira décadas do século XX, quando ele faz o seu trânsito para uma historiografia que oferece grandes modelos explicativos a partir da mudança dos padrões econômicos, será de fato uma das fontes de inspiração para os novos historiadores que começavam a se agrupar para a formação do movimento dos Annales. Deste modo, é perceptível a repercussão de Pirenne em autores como Marc Bloch.

Sabe-se ainda que foi uma conferência do historiador belga sobre as possibilidades de uma História Comparada, proferida em 1922, o que motivou Marc Bloch a escrever Os Reis Taumaturgos em 1924 (BLOCH, 1993), a primeira obra que realiza um projeto mais específico de comparativismo histórico. Desta experiência, Marc Bloch produziria os seus célebres 
artigos de 1928 e 1930 sobre a História Comparada ${ }^{8}$. O que motivara tanto Pirenne quanto Bloch a experimentar um novo olhar que transcendesse o padrão historiográfico nacionalista foi a experiência traumática da Primeira Grande Guerra. O nacionalismo havia conduzido àquele conflito de proporções ameaçadoras, e não tardaria a conduzir a outro ainda maior. $\mathrm{O}$ olhar comparado permitia a possibilidade de pensar a Europa e o mundo em uma nova perspectiva. A História da Europa: do final do império romano aos primórdios das nações ocidentais, (publicada em 1936), foi a obra de Henri Pirenne que se produziu a partir desta motivação comparativista e do desenvolvimento de sua reflexão crítica sobre o nacionalismo germânico no período em que esteve preso em um campo de concentração alemão (1916-1918).

A influência de Pirenne se prolongaria mesmo para gerações posteriores de historiadores ligados aos Annales. O exemplo de Fernando Braudel é significativo. Pirenne, no decurso de boa parte da sua produção historiográfica, atribuíra ao Mar Mediterrâneo o papel de grande protagonista histórico, capaz de mediar e de redefinir os destinos de três grandes civilizações: a ocidental-cristã, a islâmica e a bizantina. Maomé (o Islã) e Carlos Magno (o ocidente cristão) tornam-se forças antagônicas, mas complementares, precisamente através do novo padrão que se estabelece no Mediterrâneo: diante do controle islâmico do Grande Mar, e ainda incapaz para a aventura Atlântica, o ocidente europeu se interioriza e se organiza de uma nova maneira com o império carolíngio e seus posteriores desmembramentos - e a Europa marítima se transforma em uma Europa intercontinental. A mesma centralidade atribuída ao Mediterrâneo, além da capacidade de enxergar o grande Mar como um personagem que redefine os destinos humanos, reaparecerá em Fernando Braudel, que, todavia, amplia a sua visão geo-histórica em função da possibilidade de enxergar o Mediterrâneo de diversos pontos de vista (e não apenas com o olhar que parte da margem europeia deste grande mar). Para esta nova possibilidade, certamente contribuiu o fato de Braudel viver dez anos na Argélia, na outra margem do Mediterrâneo (LACOSTE, 1989, p. 177). O contato pessoal de Braudel com Pirenne (e também com a sua obra) ocorre em 1931, quando este último fora à Argélia para proferir uma conferência sobre suas famosas teses sobre as origens da Idade Média. Sobre este contato, e sobre a viva impressão que lhe causou Pirenne, registramos o depoimento do próprio Fernando Braudel:

Sua presença produzira o efeito de um explosivo. Os estudos de História, já não digo sonolentos, mas certamente sossegados e tranqüilos, viram-se agitados com a sua chegada. Mais de mil pessoas enchiam a sala da conferência. Diante do auditório, Pirenne, um pedaço de papel entre os dedos, talvez um cartão de visita, pôs-se a falar com

$8 \mathrm{Em}$ Os Reis Taumaturgos, Marc Bloch se propôs a examinar duas dinastias europeias - a Capetíngia e a Plantageneta de modo a perceber como na França e na Inglaterra desenvolvera-se uma singular crença no poder taumatúrgico dos reis, particularmente no que se refere à cura das escrófulas. Esse aspecto da obra - o comparativismo histórico - trouxe a Bloch a possibilidade de tematizar mais tarde, em um artigo de 1928 para a Revue de Sinthèse Historique, e outro datado de 1930, sobre um novo campo historiográfico que posteriormente se desenvolveria: a História Comparada. 
sua voz cheia: descia e subia o caminho do tempo, discutindo consigo mesmo, entusiasmando-se com espantosa facilidade, pescando expressões e argumentos imprevistos, com essas frases robustas e flexíveis que fazem o encantamento de seus livros (BRAUDEL, 2002, p. 1).

\section{Uma grande polêmica: a Idade Média de Pirenne}

A terceira década do século XX foi marcada por uma importante polêmica em torno da transição do mundo antigo para o ocidente medieval, do papel histórico do comércio e das cidades medievais, e da transição da medievalidade para um novo mundo que prenuncia a idade moderna. A polêmica teve como centro de gravidade algumas teses bastante instigantes propostas precisamente por Henri Pirenne. As teses de Pirenne sobre a transição da antiguidade à Idade Média, e sobre a interação entre o comércio e a Cidade Medieval a partir do século XI, causaram tanto impacto nas terceira e quarta décadas do século XX, que suscitaram inúmeras adesões de primeira hora e, particularmente nas décadas posteriores, muitas críticas provenientes de diversos lados ${ }^{9}$. Algumas das contribuições de Pirenne com este complexo de teses sobre a Idade Média foram certamente duradouras. Podemos registrá-las em suas principais linhas, com o devido distanciamento permitido por um já longo desenvolvimento historiográfico que hoje permite enxergar com maior clareza as contribuições efetivas de Pirenne para os estudos medievais.

Em primeiro lugar, (1) não há dúvidas de que foi primordial para a historiografia posterior o destaque atribuído por Pirenne à função econômica da Cidade Medieval, em contraste com a maior parte da historiografia de sua época, que então se concentrava apenas na análise institucional do fenômeno urbano. Em segundo lugar, (2) Pirenne foi um dos primeiros historiadores a valorizar, para o período medieval, o papel do mercado como elemento de fixação urbana. Nesta direção, seu trabalho rivaliza com o de Max Weber (1958), que, embora não tenha se dedicado apenas ao estudo das cidades medievais, também possui uma contribuição importante neste âmbito temático. Por fim, (3) foi particularmente importante a análise elaborada por Pirenne acerca do papel dos grandes mercadores na vida urbana medieval e na transformação do mundo feudal, além do historiador belga ter demonstrado a importância dos próprios meios rurais para o fornecimento de um contingente importante de indivíduos que se integraram à dinâmica comercial. Por outro lado, é preciso reconhecer que, para além destas contribuições indubitavelmente significativas, algumas das teses centrais de Pirenne não resistiram às críticas e investigações historiográficas encaminhadas nas décadas seguintes. Resumiremos a seguir

9 Mesmo em décadas posteriores, e ainda hoje, as críticas e polêmicas em torno das propostas de análise colocadas por Pirenne ainda movimentam discussões entre historiadores. Em 1966, por exemplo, Jan Dhondt publicou um extenso artigo com críticas às teses de Pirenne, que foi respondido em 1975 por Bryce Lyon. Ver ainda Simons (1986). 
o conjunto de teses de Pirenne, para pontuar a seguir outras indicações autorais, inclusive as mais críticas, relativas a esta grande polêmica da primeira metade do século.

As instigantes idéias de Pirenne ganharam projeção na década de 1920 a partir de duas obras principais, e também em alguns artigos elaborados e publicados na mesma época. De um lado, Pirenne apresentou suas impactantes teses sobre a renovação do comércio medieval no célebre artigo denominado Maomé e Carlos Magno (PIRENNE, 1922, p. 77-86). O artigo rediscute a fronteira historiográfica entre o mundo antigo e a Idade Média, ao colocar como centro do problema histórico a ascensão do Islamismo e a formação do Império Carolíngio. Mais tarde, em 1936, Pirenne incorporou as idéias apresentadas a um tratado mais amplo, denominado História Econômica e Social da Idade Média (PIRENNE, 1922), e na própria década de 1920 continuou produzindo artigos dentro do mesmo circuito de idéias (PIRENNE, 1923, p.223-235). A segunda obra que polarizou a polêmica em torno das idéias de Pirenne foi um pequeno mas marcante livro intitulado As Cidades na Idade Média, publicado em inglês em 1925 (PIRENNE, 1962) ${ }^{10}$. As propostas desta obra para uma compreensão das cidades medievais remontam, na verdade, a alguns artigos anteriores, que Pirenne publicara ainda no final do século XIX (PIRENNE, 1898, p.111-122). Além disto, posteriormente $\mathrm{o}$ historiador belga acrescentou a seu estudo original sobre a Cidade Medieval alguns artigos mais específicos, publicados nos primeiros números da Revista de História Econômica e da Revista dos Annales(PIRENNE, 1905, p.18).

Podemos resumir a seguir o primeiro circuito de questões (sobre a renovação do comércio medieval), que na verdade engloba o segundo (sobre a origem e natureza das cidades medievais). A idéia central é a de que, de algum modo, Maomé e Carlos Magno constituem as duas faces de uma mesma moeda no que se refere aos destinos da história da Europa Ocidental. A expansão islâmica teria neste caso condicionado diretamente o padrão que se inicia com o Império Carolíngio no Ocidente, uma vez que o modelo de comércio, as suas rotas e os seus agentes sofreram mudanças radicais após o controle muçulmano sobre determinadas áreas do Mediterrâneo. Esta retração comercial teria trazido consigo uma imediata retração urbana, o que já nos introduz no âmago do segundo circuito de questões evocadas pelas teses de Pirenne. Podemos registrar as próprias palavras do historiador belga no seu tratado sobre a História Econômica e Social da Idade Média:

Quando a invasão islâmica fechou os portos do mar Tirrênio ... a atividade municipal rapidamente se extinguiu. Salvo no sul da Itália e em Veneza, onde foi mantida graças ao comércio com Bizâncio, ela desapareceu em toda a parte. As cidades continuaram a existir, mas perderam sua população de artesãos e mercadores e, com eles, tudo o que sobrevivera da organização municipal do Império Romano (PIRENNE, 1936, p. 40).

10 Esta obra, publicada em francês em 1927, pela editora Lamertin, acrescenta textos ao livro publicado em inglês em 1925. 
Diante deste novo momento histórico, o "Estado" (expressão utilizada neste caso pelo próprio Pirenne) teve de se adaptar a uma realidade que já não contaria mais com a mesma dinâmica comercial e com a mesma rede urbana. Para este aspecto particular, pode-se retomar algumas colocações do historiador belga:

Do ponto de vista econômico, a instituição mais notável e característica dessa civilização foi o grande Estado. Sua origem, claro, é muito antiga, e é fácil comprovar-lhe a filiação a um passado muito remoto ... [...] A novidade [porém] foi a maneira como ele funcionou a partir do desaparecimento do comércio e das cidades. Enquanto o comércio foi capaz de transportar-lhe os produtos e as cidades de fornecer-lhe um mercado, o grande Estado comandou e conseqüentemente lucrou coma venda regular fora de suas fronteiras... mas agora cessava de assim agir porque não havia mais mercadores nem citadinos... agora que todos viviam de sua própria terra, ninguém se dava ao trabalho de comprar alimentos no exterior... Assim, cada Estado se dedicou ao tipo de economia que tem sido descrita, com grande inexatidão, como 'economia fechada na grande propriedade' e que foi, na realidade, simplesmente uma economia sem mercados (PIRENNE, 1936, p. 8).

As teses de Henri Pirenne sobre as modificações no âmbito comercial, a partir das mudanças políticas e econômicas que ocorriam com a expansão islâmica e com a consolidação do mundo carolíngio, levaram o historiador belga a repensar mais especificamente a história e o papel das cidades no mundo medieval. Estas proposições aparecem colocadas com muita clareza no livro As Cidades na Idade Média (PIRENNE, 1962), publicado em 1925. Podemos sintetizá-las esquematicamente: 


\section{- Síntese das proposições de Pirenne contidas em As Cidades da Idade Média(1925):}

1. Existiria uma continuidade comercial em torno do Mediterrâneo até o século VIII, abarcando Antigüidade e Idade Média pré-carolíngia. (capítulo I)

2. No período carolíngio ocorre a ruptura: os muçulmanos fecham o Mediterrâneo. Com isto, o Império Carolíngio tornar-se-á terrestre, essencialmente agrícola, e com um comércio em declínio. Este aspecto da sociedade carolíngia corresponde à outra face do surgimento do mundo império islâmico. (capítulo II)

3. As invasões normandas, no final do século IX, reforçam a ruptura. (capítulo III)

4. No que concerne à Cidade Medieval, Pirenne a conceitua em oposição aos núcleos pré-urbanos (burgos fortificados) e às persistências das civitas romanas, agora transformadas em meras sedes episcopais (para Pirenne, os atributos imprescindíveis da cidade são uma população burguesa e uma organização municipal). (capítulo III)

5. No século XI, o "Renascimento Comercial" - produzido a partir de uma "excitação externa" a partir dos contactos de Veneza e Flandres com o exterior - restabelece o Renascimento Urbano. (capítulo IV)

6. Os mercadores, atores neste conjunto de mutações, são fundamentalmente indivíduos errantes e desenraizados. (capítulo V)

7. A partir destas colocações, Pirenne generaliza um modelo de formação da Cidade Medieval: em decorrência do "Renascimento Comercial", as cidades formam-se em torno de núcleos pré-urbanos que proporcionam segurança. (capítulo VI)

8. As instituições urbanas são edificadas diretamente em torno dos interesses da burguesia mercantil. (Capítulo VII).

Estas teses, apresentadas por Henri Pirenne com uma escrita fluente e argumentativa, provocaram de imediato grande entusiasmo, mas também críticas (ainda na sua própria época, mas sobretudo nas décadas subsequentes). Com o tempo, as críticas foram superando claramente o entusiasmo que as teses de Pirenne haviam despertado em um momento inicial. Estas críticas também podem ser indicadas esquematicamente. $O$ nome de alguns autores entre parênteses é meramente exemplificativo, e objetiva apontar obras que poderão ser consultadas com relação às críticas encaminhadas. 


\section{- Principais críticas às teses de Pirenne:}

1. Críticas às teses do fechamento do mediterrâneo e do "hiato urbano" (Ganshof, R. S. López)

2. Críticas a um conceito demasiado estreito de cidade, que teria sido utilizado por Pirenne (Lewis Mumford)

3. Críticas à desconsideração do peso desenvolvimento da economia rural sobre o desenvolvimento urbano (Guy Fourquin)

4. Críticas à generalização de um modelo único de "mercador-banqueiro": o desenraizado e vindo de longe (Fourquin, Le Goff)

5. Críticas à generalização de um modelo único de formação urbana para o período medieval (desmentida por uma série de estudos de caso que mostram a variedade do fenômeno urbano medieval, sobretudo a partir da década de 50).

Henri Pirenne não se limitou, naturalmente, às suas primeiras formulações sobre o desenvolvimento comercial e urbano medieval. Em um artigo datado de 1929, dedicado a uma avaliação mais específica das cidades holandesas, o historiador belga acrescenta, às suas teses sobre o 'fechamento do Mediterrâneo', novos desdobramentos (PIRENNE, 1928, p. 18). Por um lado, (1) a irrupção do Islã teria tido uma repercussão imediata na Holanda; e, por outro lado, (2) a descida dos nórdicos sobre a Inglaterra e o continente europeu no século IX constituíram conseqüências posteriores do mesmo fenômeno. Na própria época de Pirenne, já começaram a surgir algumas críticas importantes em relação ao circuito de proposições exposto pelo historiador belga no livro As Cidades da Idade Média (1925). Norman Baynes, por exemplo, encaminhou um bem articulado conjunto de críticas num periódico importante ainda naquela década (BAYNES, 1929, p. 224-235). Antes dele, outro historiador chamado Petrusevski - já havia feito severas críticas às proposições de Pirenne. Em 1928 ele apresentou um conjunto de proposições bastante antagônico em relação às teses de Pirenne (PETRUSEVSKI, 1928, p. 468-490). Na verdade, o historiador chega a defender uma tese radicalmente oposta às proposições de 'declínio comercial' tal como haviam sido formuladas por Pirenne - chegando a se mostrar até mesmo unilateral na direção contrária. Podemos adaptar aqui um comentário bastante pertinente de Norbert Elias em O Processo Civilizador (1939):

À tese estática, segundo a qual a 'economia de troca' e a 'economia monetária' não expressaram a direção de um processo histórico gradual, mas dois estados físicos separados, sucessivos e 
irreconciliáveis da sociedade, Petrusevski opôs a tese de que jamais existiu essa tal 'economia de troca' (ELIAS, 1994, p. 279).

Ou, para citar o próprio Petrusevski (1928, p. 488):

\begin{abstract}
Não queremos discutir aqui em detalhes o fato de que, como demonstrou Max Weber, a economia de troca constituiu uma dessas utopias eruditas que não só não existem e nunca existiram na realidade, mas que, ao contrário de outras [...] que são também generalizações utopistas devido ao seu caráter lógico, jamais podem ter qualquer aplicação à sociedade concreta.
\end{abstract}

Mais adiante, Petrusevski demarca sua posição em oposição à tese de que o 'feudalismo' e a 'economia de troca' foram duas esferas, ou patamares, a última correspondendo à infraestrutura que produziu e causou a primeira. Para Petrusevski, ao contrário, os dois fenômenos nada têm a ver entre si, correspondendo isto a "idéias que se chocam inteiramente com o fato histórico, tal como o de subordinação do feudalismo à economia de troca ou sua incompatibilidade com uma organização estatal abrangente" (PETRUSEVSKI, 1928, p. 488). Outros historiadores, nesta mesma grande polêmica instigada por Henri Pirenne, empenharam-se em identificar aspectos que haviam sido negligenciados pelo historiador belga na sua generalização da história comercial e urbana do ocidente medieval. O historiador russo Rostovtzeff (ROSTOVTZEFF, 1930, p. 197), por exemplo, chama atenção para um aspecto importante que havia sido desprezado por Pirenne na sua análise das transformações econômicas na Alta Idade Média: as alterações do gosto e suas implicações comerciais. De igual maneira, surgiram os questionamentos acerca dos fatores que deveriam ser considerados prioritariamente com relação à passagem para um modelo econômico mais fechado na Alta Idade Média. H. Moss (1936), por exemplo, critica nas teses de Henri Pirenne a negligência com relação a fatores de maior duração, e interpreta a "economia de casa fechada" da Europa Ocidental nos anos 800 como "diretamente provocada pelo colapso do governo romano, das comunicações e do comércio" (MOSS, 1936, p. 209-216).

Nas décadas posteriores aos anos 1920 foram cada vez mais se estabelecendo críticas bastante consistentes a algumas das proposições de Henri Pirenne, e particularmente em relação ao questionamento da visão do mundo medieval como uma "economia de casa fechada" - o que, aliás, representava uma visão historiográfica bem típica das primeiras décadas do século XX, e que era compartilhada até então por diversos historiadores. A partir de fins da década de 1940 esta visão foi sendo relativizada cada vez mais, e naturalmente isto contribuiu para que se acelerassem as críticas a certos pontos colocados por Pirenne em suas formulações. Podemos dar dois exemplos entre outros tantos que seriam possíveis. Em um 
artigo datado de 1938, François Ganshof discute muito objetivamente a afirmação de Pirenne de que o comércio teria decaído drasticamente no Ocidente após a invasão sarracena (GANSHOF, 1938, p. 28-37). Críticas relacionadas à mesma questão são desenvolvidas em um artigo da década de 1940 por Roberto Sabatino López (LÓPEZ, 1943, p. 14-38). Posteriormente, ainda no campo da História Econômica, as críticas dirigidas às formulações de Pirenne foram se tornando cada vez mais sistemáticas. Podemos dar como exemplo uma sequência de críticas elaboradas por Guy Fourquin em relação às teses de Pirenne sobre o desenvolvimento econômico e urbano medieval (FOURQUIN, 1991, p. 239-265), que podem ser resumidas adequadamente em três grupos fundamentais.

(1) O modelo proposto por Pirenne para a revitalização urbana a partir do comércio das cidades de Flandres, e a sua descrição do modelo de crescimento urbano daí resultante, não pode ser generalizado para a maior parte da Europa Medieval. A este respeito, Guy Fourquin avalia objetivamente o mapa urbano da Idade Média central:

\begin{abstract}
Este quadro é indiscutivelmente válido para a região flamenga que Pirenne tomou para base de sua teoria, ainda que alguns portus sejam mais antigos, datando dos tempos carolíngios ou pós-carolíngios. Com efeito, por volta do ano 1000, havia poucas cidades nesta região. [...] o quadro esboçado por Pirenne é igualmente válido para as cidades forçosamente novas - dos países novos, como as cidades hanseáticas da Alemanha. Mas Pirenne, e mais ainda os seus discípulos, pretenderam alargar a sua aplicação a todo o Ocidente, por exemplo, a toda a parte norte da França (Vercauteren) ou a Inglaterra (FOURQUIN, 1991, p. 240).
\end{abstract}

(2) Nem sempre, considerando as várias regiões da Europa, teria ocorrido o tal "hiato urbano" proposto por Pirenne. Assim, segundo Fourquin, "a continuidade urbana encontrase quase sempre provada, mesmo em Flandres (Arras, Saint-Omer, Gand), desde a época carolíngia, e por vezes até desde os tempos merovíngios (como no vale do Mosa)" (FOURQUIN, 1991, p. 240).

(3) Para Fourquin, o comércio desenvolve-se com a expansão agrícola e populacional, situação que Pirenne desconsidera.

(4) Por fim, Pirenne teria ignorado outros tipos de cidade, igualmente presentes na medievalidade européia: cidades com dominância do artesanato; cidades semi-rurais (com mercadores e artesãos cultivando o campo). Fourquin encerra seu bloco de críticas com uma indagação: "Mas, vamos um pouco mais longe. Terá sido realmente a economia a desempenhar o primeiro papel em todas as cidades?" (FOURQUIN, 1991, p. 243). 
As críticas às propostas de Pirenne para a origem das cidades medievais também estiveram amplamente representadas nas décadas posteriores. De um lado, estas críticas partem da idéia de que não é possível reduzir o surgimento das novas cidades, e a revitalização das antigas, meramente a desdobramentos comerciais ou a aspectos derivados do âmbito econômico. Os historiadores da segunda metade do século XX tenderam a enfatizar, para além da história econômica, aspectos diversos relacionados à religiosidade, às mentalidades, à cultura, ou a história social de maneira geral. Podemos dar como exemplo as críticas de Lewis Mumford às teses de Pirenne sobre a origem das cidades medievais, que são basicamente de duas ordens (MUMFORD, 1991, p. 279). Em primeiro lugar, ele defende a idéia de que a origem da cidade medieval esteve associada à necessidade de uma nova forma de segurança, necessidade que foi atendida pela cidade-murada. Foi a revivescência da cidade protegida que assegurou a retomada comercial, e não o contrário (MUMFORD, 1991, p. 280). Em segundo lugar, critica a definição estreita de cidade abordada por Pirenne. "Todo esse fenômeno foi mal interpretado por Pirenne, porque ele recusava o título de cidade a uma comunidade urbana que não incentivava o comércio a longa distância, nem abrigava uma grande classe média mercantil - uma definição inteiramente arbitrária" (MUMFORD, 1991, p. 279).

Conforme vimos, algumas das principais teses de Henri Pirenne sobre a Idade Média não resistiram ao desenvolvimento posterior da historiografia. Boa parte das suas generalizações não resistiu à complexidade histórica encontrada pelas gerações seguintes de medievalistas, e diversas formulações conceituais tornaram-se não-operacionais ou inadequadas (como a noção de "renascimento comercial", por exemplo, ou a de "fechamento do Mediterrâneo"). Tampouco resistiu ao tempo a busca pirenniana de um modelo único de "ressurgimento urbano medieval", do mesmo modo que inúmeras outras explicações históricas totalizantes e unilaterais, em diversos autores da primeira metade do século XX, tenderam a serem revistas por uma historiografia que iluminou mais a diversidade e complexidade de situações históricas do que a homogeneidade de modelos unificadores ${ }^{11}$. Devemos nos perguntar, nestes momentos finais, sobre as razões para o inquestionável sucesso de Henri Pirenne em permanecer na galeria dos historiadores mais lembrados do último século. Sobre isto, de fato, ainda há algo mais a dizer.

\footnotetext{
11 De todo modo, vale lembrar que, apesar da rejeição das grandes generalizações de Pirenne para o período medieval, diversas contribuições do historiador belga para a história da Idade Média foram assimiladas. J. F. Verbruggen lembra que, "depois do artigo de Pirenne sobre 'As cidades flamengas antes do XII ${ }^{\circ}$ século', o conceito de castrum passou a ser o termo técnico para designar os castelos do condado de Flandres" (VERBRUGGEN, 1950, p. 147-155).
} 


\section{Conclusão: um historiador para o mundo}

Quando pensamos no fato de que o tempo revelou a inadequação das respostas mais específicas dadas por Pirenne às grandes questões sobre a Idade Média, não podemos nos esquecer que suas maiores lições ao mundo historiográfico se referiram precisamente à sua habilidade de propor novos problemas - em uma palavra, à sua capacidade de olhar para a história de maneira problematizada. O importante não é definir de uma vez por todas se a Idade Média começa no século VII com a ascensão do Islamismo e com uma nova configuração da Europa, mas sim entender, com Pirenne, que são os problemas propostos que redefinem as fronteiras sempre móveis entre os períodos históricos. Pirenne mostrou que havia uma nova historiografia a ser escrita: não se tratava apenas de contar os fatos ou de descrever sociedades historicamente localizadas; era preciso pensar novas conexões de modo a enxergar a história de novas maneiras. Conectar a ascensão islâmica e a interiorização carolíngia, ou o crescimento rural e a reintensificação do comércio medieval, são exemplos pirennianos de que as sequências históricas de fatos ou processos não falam por si mesmas, e que, ao contrário, adquirem novos sentidos quando contrapostas umas às outras no interior de uma análise historiográfica problematizada.

Se considerarmos que Henri Pirenne ofereceu aos seus contemporâneos novas formas de enxergar a história, novas perguntas a serem feitas e novos problemas a serem colocados, tornam-se menos importantes as respostas específicas encontradas pelo historiador belga a esta ou àquela questão. Não é de se estranhar que os jovens historiadores que iriam formar o movimento dos Annales - tais como Lucien Febvre, Marc Bloch e depois Braudel - tenham situado Pirenne na sua galeria de precursores. A nova historiografia que iria cunhar a noção de História-Problema não poderia deixar de reverenciar um historiador que surpreendeu a sua época com novos problemas. Além disto, Henri Pirenne também fora um dos historiadores que mais contribuíram para alargar definitivamente $o$ horizonte historiográfico predominante para além dos limites mais estreitos da historiografia política tradicional. Ao trazer a Economia para o centro do cenário historiográfico, Pirenne integrava-se a uma nova tendência que definitivamente gestava algo de novo, e que teria no movimento dos Annales e nas realizações historiográficas do materialismo histórico contemporâneo duas de suas maiores expressões.

Estas duas realizações - a problematização da história e a ampliação dos horizontes historiográficos - não implicaram, nas obras de Henri Pirenne, em uma perda da habilidade narrativa do historiador. Henri Pirenne foi também um mestre da escrita historiográfica, e essa lição ainda ressoa nos dias de hoje. Quando se verifica uma certa perda de estilo historiográfico em muitos dos historiadores econômicos das últimas sete décadas, vem à mente a sua contrapartida: Henri Pirenne, um historiador econômico que não abriu mão de um estilo fluente, sedutor, ou mesmo literário - capaz de discutir as relações econômicas ao mesmo tempo em que nos fazia seguir as trajetórias de vida de mercadores que deixaram 
seus vestígios nas fontes, ou de estender o olhar para a amplidão do Mediterrâneo como mais tarde o faria Fernando Braudel, entretecendo uma história na qual as próprias cidades se transformavam em grandes personagens de um enredo maior. Pirenne, seguramente, é mais um elo na grande cadeia de historiadores que foram também grandes escritores. Esta lição, em seus diversos livros e artigos, continua sendo uma contribuição notável à comunidade sempre renovada de historiadores.

Há algo mais a dizer sobre as grandes generalizações de Pirenne. Na verdade, estas encobrem outro aspecto importante: a motivação de escrever uma história global, não relacionada a apenas um país ou a uma localidade específica. Conforme acentuamos antes, houve um sutil deslocamento de um Pirenne historiador nacional, especificamente belga - o mesmo que estava particularmente preocupado com As Origens do estado Belga (PIRENNE, 1906) ou com As cidades flamengas do século XII (PIRENNE, 1905) - a um Pirenne historiador da Europa, que introduz as primeiras grandes preocupações em favor de uma nova modalidade historiográfica, a História Comparada, ao lado de outros autores que logo lhe seguiriam, entre os quais o próprio Marc Bloch. Uma sinalização pioneira para uma perspectiva comparatista, na alvorada de uma historiografia que logo reservaria um lugar de honra para a modalidade da História Comparada, pode ser indicada como outra das grandes contribuições de Pirenne que o fariam sobreviver às críticas mais implacáveis desfechadas contra as suas teses específicas sobre a Idade Média.

Como ocorreu a vários outros historiadores que vivenciaram o período das guerras mundiais, o que despertou em Pirenne o impulso para o olhar comparado foi a urgência de erguer a visão historiográfica para além dos limites nacionais - que de certo modo haviam resultado não apenas no nacionalismo historiográfico, como também no nacionalismo belicista. $O$ insight nesta direção ocorre a Pirenne no período em que esteve preso pelos alemães nos anos finais da Primeira Grande Guerra, entre 1916 e $1918^{12}$. Este período de aprisionamento no contexto da guerra pode ser mesmo indicado como um divisor de águas na historiografia de Pirenne, ou como o doloroso momento em que Pirenne se vê compelido a deixar de ser um historiador belga para se tornar um historiador para o mundo. A reflexão sobre os horrores daquela grande guerra, para a qual os europeus haviam sido conduzidos sob a égide dos nacionalismos exacerbados, levariam Henri Pirenne ao projeto de escrever uma História da Europa, das invasões ao século XVI (PIRENNE, 1936) - quem sabe o desesperado anseio de encontrar as origens do esfacelamento de uma unidade maior, e ainda, talvez, o angustiante desejo de reencontrar esta unidade européia no futuro. Estas inquietações também foram acompanhadas de uma reflexão mais específica sobre as potencialidades do Método Comparativo em História, que finalmente se concretizou em uma conferência em 1923, um ano antes de Marc Bloch se entregar à tarefa de redigir Os Reis Taumaturgos (BLOCH, 1993), a primeira "história comparada-problema". De igual maneira, os artigos de Pirenne que ressurgem com força total na década de 1920 - após um

12 Sobre esta passagem de Pirenne pelo período da Primeira Guerra, ver Violante (1997) e Lyon (1974). 
significativo silêncio que pode ser comprovado com o exame cronológico de sua produção bibliográfica - indicam doravante questões mais gerais, que dizem respeito a toda a Europa, e não apenas a Bélgica.

Hoje, devemos nos perguntar se as grandes generalizações de Pirenne sobre a Idade Média também não encobriam este mesmo anseio de pensar a Europa em uma perspectiva mais ampla. Ao desconsiderar as realidades locais - que depois tantas vezes lhes seriam cobradas pelos seus maiores críticos -, ou ao tentar subsumi-las em uma generalização mais ampla, não estaria se expressando em Pirenne a inquietante busca de pensar a História da Europa como um grande movimento, à maneira de preparar-se para pensá-la como um grande povo? Nestes tempos recentes, entre as últimas décadas do século XX e as primeiras do século XXI, quando convivemos com os esforços dos diversos países europeus em constituir uma difícil unidade européia, podemos ser mais condescendentes em relação às grandes generalizações de Pirenne sobre as origens da Idade Média e sobre a história das cidades e do comércio internacional. Não é difícil compreender que a incansável busca de uma humanidade comum, contra os diversos contextos contemporâneos que a fragmentam, tem sido talvez o principal aspecto que tem permitido a inabalável persistência de Henri Pirenne na galeria dos grandes historiadores de todos os tempos. Se ao começarmos a analisar a contribuição historiográfica de Henri Pirenne começamos por percebê-lo como um historiador belga, ao avançarmos nesta mesma análise não há como deixar de percebêlo, em seguida, como um historiador europeu. Por fim, Henri Pirenne termina por se afirmar em uma dimensão ainda mais ampla, a de um historiador para o mundo.

\section{BIBLIOGRAFIA}

\section{Obras de Henri Pirenne}

PIRENNE, Henri. 1885. De l'organisation des études d'histoire provinciale et locale en Belgique, Westdeutsche Zeitschrift für Geschichte und Kunst, IV, 1885, p.113-138.

PIRENNE, Henri. 1895. Origine des constitutions urbaines au Moyen Age. Revue Historique, tit. LVII. Paris, p.52-ss.

PIRENNE, Henri. Villes marchés et marchands au moyen age. Revue Historique, Paris, v. 67, p. 111-122, 1898.

PIRENNE, Henri. 1900-1931. Histoire de Belgique. Bruxelas: Lamertin, sete volumes. 
PIRENNE, Henri. Les villes flamandes avant le XII siècles. Annales d'Est et du Nord, Paris, v. 1, p.18, 1905.

PIRENNE, Henri.Les origines de l'état belgue. Bruxelles: Desoer, 1906.

PIRENNE, Henri. 1910. Les anciennes democraties des Pays-Bas. Paris: Flammarion.

PIRENNE, Henri. Mahomet et charlemagne. Revue Belgue de Philologie et D'histoire, Local, n. 1, p. 77-86, 1922.

PIRENNE, Henri. Un contraste économique: merovingians et carolingians. Revue Belgue de Philologie et D'histoire, Local, n. 2, p. 223-235, 1923.

PIRENNE, Henri. 1923. "De La méthode comparative en histoire" In: DES MAREZ, G. e GANSHOF, F-L (orgs). Compte-rendu du V Congrès des Sciences Historiques. Ghent: Weissenbrusch, p.19-32.

PIRENNE, Henri. 1925. Medieval Cities: Their Origins and the Revival of Trade. Princeton: Princeton University Press.

PIRENNE, Henri. As cidades na idade media. Lisboa: Europa, 1962.

PIRENNE, Henri, 1929. The Place of the Netherlands. Economic History Review, II, $\mathrm{n}^{\circ} 2$, p.2040.

PIRENNE, Henri. 1930. Les villes et les intitutions urbaines, 2 vol. Paris / Bruxelles: Felix.

PIRENNE, Henri. 1933. Histoire Économique et sociale Du moyen âge. Vol VIII In: GLOTZ, Gustav (org), Histoire Générale. Paris: Gustav Glotz.

PIRENNE, Henri. Histoire de l'Europe:- des invasions aux XVI siècle. Bruxelles: Neuchâtel, 1936.

PIRENNE, Henri. 1936. Economic and Social History of Medieval Europe. London: Trubner. PIRENNE, Henri. 1992. Mahomet e Charlemagne. Paris: Quadrige [original: 1937].

PIRENNE, Henri. 1951. Histoire Économique de l'occident medievale. Brugues: Coornaert. 


\section{Referências}

ARNDT, Ernst. Moritz (1877). Geist der Zeit [Espírito do Tempo]. Altona: Hammerich, 1986. [original: 1806].

BACHRACH, B.S. Pirenne and Charlemagne. In: MURRAY, A.C. (Org.). After Rome's Fall. Narrators and Sources of Early Medieval History. Toronto: University of Toronto Press, 1998. p.214-231.

BAYNES, Norman H. Review of Lot, Pirenne and Rostovtzeff. Journal of Roman Studies, vol.19, $\mathrm{n}^{\circ} 2$, January 1929, p.224-235

BLOCH, Marc. Os reis taumaturgos. São Paulo: Companhia das Letras, 1993.

BLOCH, Marc. "Pour une histoire comparée dês sociétés européenes". Revue de Synthèse Historique. Paris: La Renaissance du Livre, 1928. p.15-50, t. 46.

BLOCH, Marc. Comparaison. Bulletin du Centre Internacional de Synthèse, Paris, n. 9, jun/1930.

BLOCH, Marc. Apologia da historia. Rio de Janeiro: Zahar, 2001.

BRAUDEL, Fernand. O Mediterrâneo e o Mundo Mediterrânico. São Paulo: Martins Fontes, 1984. [original: 1949, revisto em 1965].

BRAUDEL, Fernand. Henri Pirenne. Revista de História, São Paulo, n. 46, jul. 2002. Disponível em:<http://ning.it/w5PbUW>. Acesso em: 5 out. 2013.

BROWN, E. A. R. Henri Pirenne: a Biographical and Intellectual Study. History and Theory, v. 15, n.1, p.66-76, 1976.

DESPY, G.; VERHULST, A. (Org.). La fortune historiographique des thèses d'Henri Pirenne. Archives et Bibliothèques de Belgique, Bruxelles, n. 28, 1986.

DHONDT, Jan. Henri Pirenne: historien des institutions urbaines, Annali della Fondazione Italiana per la Storia Amministrativa, III, p.81-129, 1966.

ELIAS, Norbert. O processo civilizador. Rio de Janeiro: Zahar, 1994.

FOURQUIN, Guy. As cidades e o setor secundário. In: História economica do ocidente medieval. Lisboa: Edições 70, 1991. p. 239-265.

GANSHOF, François..Henri Pirenne: le mâitre, l'historien. Bruxelas: Editions du Flambeau, 1936a. 
GANSHOF, François. Henri Pirenne and Economic History. Economic History Review, Local, v. 6, p. 179-185, 1936b.

GANSHOF, François. Note sur les ports de Provence du VIII au X siècle. Revue Historique, Local, v. 183, p. 28-37, 1938.

GENICOT, Leopold. Henri Pirenne. In: BURGUIÈRE, André. Enciclopédia das ciências historicas. Rio de Janeiro: Imago, 1993. p. 597-599.

IGGERS, Georg G. The German Conception of History: The National Tradition of Historical Thought from Herder to the Present. Hanover: Wesleyan University Press, 1988.

KURTH, G. Henri Pirenne, Geschichte Belgiens, Gotha, Perthes. Archives Belges, n. 1, p. 21-25, 1899.

LAURENT, Henri. Les travaux de M. Pirenne sur la fin du monde antique et les débuts du Moyen Age. Byzantion. Revueinternationale des études byzantines, t. 7, p. 495-509, 1932.

LACOSTE, Y. Braudel geógrafo. In: . Ler Braudel. Campinas: Papirus, 1989. p. 175-219.

LAMPRECHT, Karl. What is history? five lectures on the modern science of history. New York: Macmillan Co, 1905.

LYON, B. Henri Pirenne: a biographical and intellectual study. Gand: Story-Scientia, 1974.

LYON, B. L'œuvre de Henri Pirenne après vingt-cinq ans, Le Moyen Age, n. 66, p.437-493, 1966.

LYON, B. A Reply to Jan Dhondt's Critique of Henri Pirenne. Handelingen der Maatschappij voor Geschie-denis en Oudheidkunde te Gent, v. 29, p.3-25, 1975.

LYON, B. Henri Pirenne: Connu or Inconnu?. Revue Belge de Philologie et d'Histoire, v.81, p.1231-1241, 2003.

ESPINAS, G. 1946. Les origines du patriciat urbain. Henri Pirenne s'est-il trompé?. Annales ESC, vol.1, n², p.143-153.

LE GOFF, Jacques. 1992. O Apogeu da Cidade Medieval. São Paulo: Martins Fontes [original: 1980].

LÓPEZ, Roberto Sabatino. Mohammed and charlemagne: a revision, Speculum, v. 18, p. 14-38. 1943. 
MOSS, H. L. B. The economic consequences of the barbarian invasions. Economic History Review, v. 7, p. 209-216, 1936.

MUMFORD, Lewis. A cidade na historia. São Paulo: Martins Fontes, 1991.

PETRUSEVSKI, D. M. Strittige Fragen der mittelalterlichen verfassungs und wirtschaftsgeschichte. Zeitschrift für die Gesamte Staatswissenschaft, Tübingen, v. 85, p. 468-490, 1928.

ROSTOVTZEFF, Michael. The decay of the ancient world and its economic explanations. Economic History Review, n. 2, p. 197, 1930.

SIMONS, Walter. La fortune historiographique des tèses de Henri Pirenne. Archives et Bibliothèques de Belgique, Brussels, v. 28, p. 1, 1986.

VERBRUGGEN, J. F. Notes sur le sens des mots castrum, castellum, et quelques autres expressions qui désignent dês fortifications. Revue Belge de Philologie et D'histoire, v. 28, n. 1, p. 147-155, 1950.

VIOLANTE, Cinzio. La fine della "grande illusione". Uno storico europeo tra guerra e dopoguerra, Henri Pirenne (1914-1923). Per una rilettura della Histoire de l'Europe. Bologne: Instituto Trentino di Cultura, 1997.

WEBER, Max. The city. New York: Macmillan, 1958. 